\title{
Main Influence Factors for Penetration Rate in Tunnelling
}

\author{
Kyoung-yul Kim, Hee-hwan Ryu, Dae-soo Lee \\ KEPCO Research Institute \\ 105, Munjiro Yoosung, Daejeon, South Korea \\ xgo.com@gmail.com; hhryu82@kepco.co.kr; leeds400@kepco.co.kr
}

\section{Extended Abstract}

The target of this study is to establish the influence factors for penetration rate of soft rock in EPB shield TBM tunnel site. The tunnelling site is located at Kyoung-Ki province in South Korea. The bed rock is a banded gneiss of the Cenozoic Tertiary metamorphic rock. The depth of TBM lateral tunnel is about $50 \mathrm{~m}$ from the ground surface, there is no underground water in this site. Total length of lateral tunnel is $2.26 \mathrm{~km}$, outside diameter of tunnel is $3.0 \mathrm{~m}$. TBM for excavation, which was made by KAWASAKI from Japan in 2013, has capabilities of maximum RPM 9, total thrust $9,600 \mathrm{kN}$ and curve radius $120 \mathrm{~m}[3]$.

To analyse the main influence factor for the penetration rate in situ excavation data, stepwise regression analysis was conducted. The input data are total 15 factors, such as eight ground factors including TCR, RQD, Lugeon, Absorption, Elastic velocity, UCS and Young's modulus[1], and seven TBM factors including thrust, Jack pressure, RPM, Torque, cutter rotation pressure, screw torque and face earth pressure[2]. The machine raw data of TBM data acquisition system based on the excavation length of about $1,600 \mathrm{~m}$ is used, ground conditions are obtained from the boring log data. Some characteristics of ground condition are that the extent of UCS of bed rock is $20 \mathrm{MPa}$ to $97 \mathrm{MPa}$ and the range of RQD is 53 to 96 . Some operating conditions of TBM are that the average RPM is about 7.1 and the range of total thrust is $1,500 \mathrm{kN}$ to $3,000 \mathrm{kN}$.

To begin with, basic statistical analysis is performed on the response variable which is penetration rate prior to statistical analysis. The results show the normal distribution with an average penetration rate of $31.2 \mathrm{~mm} / \mathrm{min}$ and a standard deviation of $8.8 \mathrm{~mm} / \mathrm{min}$. And then stepwise regression analysis is performed to find the main influence factors among various factors. From the stepwise regression analysis, it is found that RQD, Young's modulus, RPM and total thrust are the main influence factors affecting penetration rate of the Shield TBM tunnel in this soft rock site. At this time $\mathrm{R}$-sq is 99.6 and Mallows C-p is 3.6. Using the developed regression formula, the remaining excavation rate range is estimated as $21.4 \mathrm{~mm} / \mathrm{min}$ to $32.9 \mathrm{~mm} / \mathrm{min}$. After excavation $400 \mathrm{~m}$ length tunnel, real penetration rate is recorded to range $18.1 \mathrm{~mm} / \mathrm{min}$ to $31.0 \mathrm{~mm} / \mathrm{min}$ depending on the ground conditions in tunnel.

\section{Acknowledgement}

This research was supported by a grant (16SCIP-B105148-02) from the Construction Technology Research Program funded by the Ministry of Land, Infrastructure, and Transport of the Korean government.

\section{References}

[1] Korea Electric Power Corporation, "Ground Survey Report of Cable Tunnel”, 2013.

[2] Korea Electric Power Corporation, "Raw Data Set from EPB Shield TBM", 2016.

[3] Korea Electric Power Corporation, "Design Cable Tunnel \& Selecting TBM", 2015. 